\title{
Practice and Reflection of Dialogical Teaching of Reading - Analysis on Chinese microteaching cases carried out by students majoring in primary education in normal colleges
}

\author{
Haixia Li \\ College of Teacher Education, Mudanjiang Normal University, Mudanjiang, 157012, China
}

\author{
Keywords: Dialogue. Text. Teacher
}

\begin{abstract}
Students majoring in primary education in normal colleges have their own perspectives of dialogical teaching of reading, thorough or shallow, correct or partial, and they try to put it into their Chinese microteaching practice in primary school. Through summarizing and rethinking the practice, they deeply understand the further significance of the dialogical teaching of reading, which becomes the foundation of the continuing exploration.
\end{abstract}

\section{Introduction}

It is underlined in the 2011 version of Chinese Curriculum Standard in Compulsory Education that "Chinese teaching should be carried out in the course of equal dialogues between teachers and students”. Hence it can be seen that after summarizing ten years of teaching experiences, dialogical teaching of reading in Chinese teaching is still a consistent principle encouraged by the new curriculum. Through multiple dialogues between students and students, teachers, editors and texts, dialogical teaching of reading enables students to understand and master the knowledge and the process to obtain the knowledge, to cultivate cooperation spirit and eventually to "Learn to study, learn to live, learn to recognize and learn to behave" [1]. The curriculum - methods of primary school's Chinese teaching in normal colleges keeps up with the pace of the Chinese curriculum reform in compulsory education, focusing on guiding students to apply the teaching mode to their microteaching practice on the basis of leading students to understand the theory of dialogical teaching of reading. From the students' microteaching practice in recent years, the pre-teachers have had the awareness of "dialogue”. Pursuing the "dialogue” always companies their teaching process. However, there are many drawbacks during the actual practice due to various reasons.

\section{Equating the simple question and answer to dialogue.}

“Through a dialogue, the concept of students' teachers and teachers' students no longer exists. A new term is created, that is students as teachers or teachers as students." (2) However, some pre-teachers design a series of questions in lesson preparation and predesign and the ultimate teaching goal is to do everything possible to lead students to give the same answer as predesigned. The appearance of this process is that the students' initiative is fully developed and there are some interactions between teachers and students. But in fact, students are passively led by teachers, which would encourage students' inertia of thinking. No vitality exists in such classes.

\section{The inadequate preparation of the dialogue session.}

To finish microteaching tasks, some pre-teachers design the dialogue section in according to scoring criteria. However, they did not print and distribute the relative texts to all cooperative students in advance. In consequence of lack of teaching material, the dialogue becomes formal and the understanding is literal and separated from textbook. The meaning is thus greatly reduced. In addition, even when there is plenty of teaching material, they just rush to dialogue. Teachers ask questions first. Then students read the text, think about the questions and find the answers in two or 
three minutes. Such quick dialogues cannot realize the real heart-to-heart communication. The students have not read the basic text thoroughly yet, even far from deeply exploring.

\section{Group discussion in class becomes a mere formality.}

Microteaching is a kind of teaching practice carried out among college students. Thus the cooperating students are at the same age as pre-teachers, which means their past life and study experiences let them be very familiar with the content of primary Chinese reading teaching, and they can easily understand the topic of group discussion set by teachers. So as soon as the teachers' instructions are announced, the classroom becomes lively and students start to talk to each other loudly. But if you observe carefully, you will find that almost all of the cooperating students are absent-minded and undisciplinedly casual. Most of them are chatting and several are playing with mobile phones. They are not discussing at all. At the end, group discussion hastily winds up a matter. Most of pre-teachers would be frustrated during this section and they fail to catch the essence of group discussion in class. That is regret.

\section{Teachers cannot understand texts precisely themselves.}

The content of primary Chinese texts is relatively easy. But it has some certain, irreplaceable value and significance to be chosen and compiled into textbooks as classic. Compilers devoted their care and thought to it. However, some pre-teachers are blundering. They cannot read up texts carefully and they cannot study each word, phrase, paragraph, article, or even every single punctuation. Therefore they cannot deeply grasp the theme and connotation of the texts deeply, or they might distort and deviate from the compiler's intention. Or some other circumstances occur. That would cause them unable to give correct judgments of students' answers. For instance, when teaching about a text of grade two - A Fox and a Tiger, the teacher designed a performing section, letting students perform "high and mighty", "shake the head and wag the tail" and other two phrases. But the teacher himself cannot understand those phrases precisely and he could not give the proper instruction to students. Thus though the students' rough performance actives the class, it is not helpful for students to understand the meaning of texts.

To avoid the above summary drawbacks in dialogical teaching of reading carried out by students majoring primary school teaching, improvement measures are proposed as follows:

\section{To improve theoretical accomplishment}

Theory leads behavior. With profound educational theories, students' microteaching practice will have stronger purposiveness and operability. For example, after grasping that the feature of dialogicality of the dialogical teaching of reading, a clear understanding of relationship among students, teachers, compilers of textbooks and texts would come to your mind. Teachers are students' learning community. Teaching benefits teachers as well as students. It is only through equal communication and exchanging that students would give full play to their initiative, the class teaching's characteristics of democracy, cooperativeness and realness would be fully reflected, and students' independent Chinese ability would be cultivated.

\section{To cultivate the sense of cooperation}

Many people think that to realize dialogical teaching of reading, group discussion must be used more to manage the teaching in class. So in microteaching process, pre-teachers are keen on designing the group discussion section. But due to students' lack of cooperative sense, the section is practically no function and barely has any effect. That requires everyone to respect others' fruits of labor. On the one hand, cooperative students should correct their attitude to treat every microteaching class seriously, take notes carefully and fill in the evaluation card for fair scoring. On the other hand, pre-teachers need to prepare adequate teaching material. Besides preparing diverse teaching tools, they should print and distribute teaching texts to students so that class teaching will have a material base, and group discussion will be easily carried out.

To be based on texts and delve into texts 
As a qualified primary Chines teacher, the most basic professional quality is to delve into texts. It is well known that Chinese characters contain profound traditional culture. Authors and compilers placed their deep meaning on articles consist of Chinese characters. So no matter how rich the class teaching methods are, teachers should be based on texts and delve in to texts. That's the teaching principle Chinese teachers in primary schools must abide by. For example, when teaching about the lesson Uncle Lei Feng is With Us, the teacher asks the question based on the text, "What did the brook see?” Then the teacher leads students to find three important words in the text- along, follow and riding, and to think about the words. The teacher writes on the blackboard. After that, they go on to find the words muddy, thorns and warm and think about the words. In such a methodic teaching process, the text is expanded layer by layer and thereupon the spirit of Lei Feng ripples each one's heart. Because the teacher seizes the key point of teaching content exquisitely to manage the teaching, the teaching effect is very good.

\section{To exercise to be resourceful}

Curriculum resource generated in class will have infinite teaching potential once being guided by teaching wisdom. However it has the features of uncertainty, instability and so on which are the same as the features of random questions and situations caused by dialogues in dialogical teaching of reading. Pre-teachers are lack of teaching experience and their knowledge and resource pool are still being formed. So it is difficult for them to deal with the above questions and situation. Their minds might go blank when facing that kind of questions, or they might neglect the questions out of panic. In fact, the most important path to handle this kind of generated questions well is to enrich your knowledge and resources, to accumulate, to study indirect teaching experience extensively, to rethink your teaching experiences and lessons, and to ponder carefully. Then your resourcefulness in class will be improved gradually.

\section{The questions designed should be scientific}

Catechetical teaching cannot be equated with dialogical teaching. But questions are necessary in the dialogical teaching process. In dialogical teaching of reading, the ultimate goal of questioning is to inspire students' positive thinking, to develop good habits of good thinking, so as to improve students' thinking quality. So in dialogical teaching of reading, the questions should be designed step by step so that the students can be guided to understand the texts and to explore the essence of the texts progressively. Therefore the students will understand the texts more naturally and more deeply. For example, when teaching about the lesson Uncle Lei Feng is With Us, the teacher asks, "Brook, did you see uncle Lei Feng?" "What was he doing when you saw him?" "Do you think uncle Lei Feng is doing hard work? How can you tell that?” The questions are progressive, which makes the short article leave meaningful afterthoughts to us.

In conclusion, dialogical teaching of reading, as a new teaching mode, should be paid great attention to and promoted actively. Students majoring in primary education in normal colleges have the courage to try it in microteaching. That spirit of exploring is creditable. But after all, they are lack of practical teaching experience of forefront position, which causes various and inevitable deficiencies in teaching. That is why the pre-teachers need to study repeatedly and explore in their own teaching practice in order to improve the ability to operate the mode and thereby improve teaching efficiency of primary Chinese class.

\section{References}

[1] Wu Shiyun: Specific Implementation of Dialogical Teaching, Education and Management in Primary and Middle School. 2005,8, p12

[2] Bai Suping: Dialogue: A New Realm of Teaching of Reading, Research on Chinese Teaching. 2005, 5, p12 